\title{
Lisboa e os seus cinemas. Gestos, práticas e espaços de uma afinidade Patrícia Santos Pedrosa ${ }^{1}$
}

Margarida Acciaiuoli. 2012. Os Cinemas de Lisboa. Um fenómeno urbano do século XX. Lisboa: Bizâncio. 384pp. ISBN: 978-972-53-0518-8.

O objetivo deste texto é apresentar e refletir sobre o livro Os Cinemas de Lisboa. Um fenómeno urbano do século $X X$, da historiadora de arte Margarida Acciaiuoli (n. 1948), publicado no final de 2012, pela Bizâncio. Organizado em seis partes, que vão cronologicamente do final do século XIX até ao princípio do século XXI, vai desfiando, com enquadramento amplo, a relação próxima entre a cidade e os espaços onde a história do cinema também acontece e pode ser contada: os cinemas.

Investigar determinada tipologia arquitetónica resulta com facilidade em leituras estritas de desenho e estratégias projetuais e formais da mesma. Uma compreensão formal ou funcional, por exemplo, pode concentrar o olhar lançado, reduzindo-o a um fragmento que confere determinado destaque numa discussão que se quer mais alargada. Conseguir trabalhar um determinado conjunto de edifícios, com um programa particular, desde a sua implantação confusa até à sua glória e, posteriormente, reinvenção, não perdendo nunca de vista a necessidade de o relacionar com a vida social, cultural e profundamente urbana que o caracteriza, é uma necessidade para garantir que os estudos da cidade e das arquiteturas são efetivos e complexos, como merecem sê-lo.

É esta visão da arquitetura e da cidade, compreendidas como acontecimentos intricados, densos e carregados de múltiplas leituras e inter-relações, que se procura sublinhar na leitura efetuada deste livro. A estratégia desta recensão, para lá desta ênfase anteriormente referida, procura também, e a favor de uma certa operatividade da mesma, sublinhar conteúdos e elementos âncora para a compreensão do livro em causa.

A primeira parte do livro começa relatando a chegada a Lisboa, via Madrid, do que se designou, à época, de "fotografia viva" (19); a estreia do animatógrafo, no Real Coliseu, situado na Rua da Palma, acontece em 1896. Com este momento se inicia o primeiro dos capítulos d'Os Cinemas de Lisboa. Como aponta o subtítulo - Um fenómeno urbano do século $X X-$, a leitura proposta enquadra as salas

\footnotetext{
${ }^{1}$ Universidade Lusófona, Departamento de Arquitetura + Labart, ECATI, ULHT, Campo Grande, 376, 1749-024, Lisboa, Portugal.
} 
enquanto palcos de acontecimentos culturais, sociais e espaciais, em estreito cruzamento com a vida urbana que acompanha a história das salas de cinema lisboetas. Assim, nos últimos anos do século XIX, primeiramente analisados, é-nos feito o relato de uma cidade que vai recebendo a projeção de imagens em movimento como parte de uma diversificada oferta de divertimentos que incluem, por exemplo, o circo ou o teatro de variedades. Em paralelo com as práticas, os espaços ainda não se encontram num processo de especialização, antes apostando na flexibilidade programática e no improviso. Já nos primeiros anos do século XX, a primeira parte deste volume encerra apontando o aparecimento da necessidade de adaptação dos teatros a salas de cinema, marcando uma efetiva viragem no papel do cinema.

Com o surgimento, em 1924, do Cinema Tivoli, projeto de Raul Lino para o início do eixo mais nobre da capital, fixa-se um momento charneira no que é a "ida ao cinema" como gesto com valor em si mesmo. À dignidade do edifício e à nobreza da implantação junta-se a autonomia da prática social e cultural dos que podiam economicamente aceder a este momento de convívio e diversão. Em 1931, abre ao público, no coração do Parque Mayer, o vizinho Cinema Capitólio, de Cristino da Silva, apresentando diferentes estratégias urbanas e arquitetónicas. De linguagem formal despojada e sem oferecer a fachada diretamente à Avenida da Liberdade, será, segundo a autora, outra sala que se constituirá como marco.

Nesta segunda parte do livro são apontados estes dois edifícios que se consolidam como referência no território da cidade, mas é referido também um outro fenómeno que marcará a relação das salas de cinema com a cidade de Lisboa: o surgimento e a proliferação das salas de cinema de bairro e do seu papel de proximidade social e urbana. Pela extensa lista de exemplos abordados percebe-se que as especificidades dos bairros iam orientando as características das próprias salas construídas: dimensões, caráter urbano, linguagem arquitetónica ou filmes em cartaz eram fatores diferenciadores, de caso para caso.

Ao longo e complexo percurso de projeto, construção e apropriação pela cidade do Éden-Teatro, inaugurado nos Restauradores em 1937, é dedicado todo um capítulo. Ainda que sendo as primeiras versões da autoria de Cassiano Branco, acaba por ser concretizado sob ação de Carlos Florêncio Dias. O final dos anos 1930 e o início da década seguinte são marcados por uma alteração, segundo a autora, que implica uma "revisão do estatuto das salas" (159), associada à própria alteração do Éden-Teatro para sala de cinema, logo em 1938. O interesse pelo cinema em sentido alargado, que incluía as estrelas e as suas vidas ou os filmes como objetos de reflexão, cresce e ganha adeptos.

A construção do Cinema São Jorge, da autoria de Fernando Silva, vai quebrar um interregno longo na construção de equipamen- 
tos desta natureza na capital. Apesar da caracterização espácioarquitetónica cuidada e de mais uma digna e impactante frente de rua que assim surgia, foram as novidades técnicas e de conforto que o edifício apresentava que mais impacto causariam. Em termos de resposta à maturidade deste programa arquitetónico, a ausência de caixa de palco esclarece sobre a intenção de partida: uma grande e notável sala de cinema. Esta sua característica, como é explicado no livro, configura uma clara exceção ao contexto das salas da capital e do país.

No percurso de compreensão das salas referidas como as grandes "catedrais" (182), o Cine-Teatro Monumental é incontornável. Numa tentativa de salvaguardar os espaços para apresentações teatrais, tanto os hábitos, como as pressões legais e políticas, iam apontando no sentido da construção e manutenção dos programas duplos que os cineteatros representavam.

As orientações oficiais que norteiam o processo de construção do Cine-Teatro Monumental, no Saldanha, do arquiteto Rodrigues de Lima, não fogem à regra. Começado o projeto em meados de 1940, só no final de 1951 será inaugurado. A entrada nos hábitos dos lisboetas, tanto pela via do cinema como do teatro, é resultado efetivo deste êxito do espaço.

Se o Monumental já refletia, em termos de posição relativa, uma cidade que se desenvolvia e crescia pelo eixo nobre marcado pelas avenidas da Liberdade e Fontes Pereira de Melo, no outro eixo menos nobre, no sentido da Avenida da República e do Campo Pequeno, surgia o Cinema Império, que viria a ser inaugurado em 1952. Virado de modo franco para a Alameda D. Afonso Henriques, colocava-se na interseção desta com a Avenida Almirante Reis. Neste caso, a opção pela sala única de dupla utilização foi a escolhida por Cassiano Branco, quando, em 1945, lhe foi encomendado o projeto. Virado inicialmente para a avenida, é posteriormente garantida o acesso pela alameda, num sentido que responde às vontades oficiais de fazer com que a Alameda D. Afonso Henriques seja maximamente valorizada. Depois de 1947 e de mais uma proposta, Cassiano Branco abandona o projeto e é o arquiteto António Varela que coloca o grande envidraçado na fachada principal e redesenha as escadas de acesso na mesma. Também este arquiteto abandona o projeto e serão Frederico Jorge e Raul Chorão Ramalho a continuá-lo. O Cinema Império, num sentido de adaptação aos novos tempos, passa a contar com um estúdio no topo do edifício, em 1960.

A quinta parte do livro debruça-se sobre "Os cinemas na expansão da cidade”. A contribuição principal deste capítulo é perceber como este equipamento se ia articulando com as zonas de desenvolvimento de Lisboa, localizadas longe do centro. São quatro os principais exemplos apresentados: o Cinema Alvalade (Avenida de Roma), o Cinema Roma (Praça de Londres), o Cinema Restelo (En- 
costa da Ajuda) e o Cinema Lumiar (Calçada de Carriche). O primeiro caso será talvez o mais paradigmático por surgir de modo precoce num território pensado desde 1945 , que se vai paulatinamente concretizando e que tem na sala de cinema, da autoria de Filipe Figueiredo e Lima Franco e inaugurado em 1953, um dos seus primeiros equipamentos. A consolidação deste território novo encontrase associada a uma crescente vida de bairro onde o cinema complementa e contraria, junto com o comércio local, o mercado ou os cafés, o caráter dormitório que algumas zonas de expansão vão adquirindo. Cada um destes casos, tal como já se tinha encontrado nos cinemas de bairro antes referidos, são situações cujas características se associam intimamente ao território em que se nascem e que ajudam a consolidar.

Se estes objetos profundamente urbanos, com arquiteturas que funcionavam e se valorizavam pelas multidões que neles assistia às sessões de cinema e por eles circulavam, se impõem procurando plasmar um lado moderno da vida citadina, também sofrerão um revés importante com o aparecimento e difusão de um novo e poderoso eletrodoméstico: a televisão. Neste sentido, uma crise de espectadores orientará a procura de novas soluções, mais capazes de resistir economicamente.

Refletindo sobre o que anteriormente é analisado, a autora sublinha, no início da sexta e última parte do livro, a relação próxima entre salas, espectadores e arquitetura dos edifícios das primeiras. Deste modo, o caráter urbano dos cinemas foi estando garantindo ao longo de várias décadas. No final da década de 1950 alterações legislativas vão permitir uma mudança importante, com o modelo dos cineteatros a ser ultrapassado. Passa a ser possível construir, por exemplo, salas de cinema em edifícios de comércio e de habitação. Surgem assim novos espaços, aproveitando zonas impensáveis anteriormente, sem a necessidade de serem assinalados urbanamente por uma fachada, um rosto, associado à função. Mas também se assiste à compartimentação de algumas das grandes salas, alterando-lhes de modo irremediável os espaços e a referência que souberam ser. Uns e outros refletem a procura do modelo do estúdio que chegara a Portugal com força.

A partir da década de 1970 começam a surgir os exemplos de integração das salas de cinema nos centros comerciais. Esta década e a seguinte assistem a uma proliferação destes espaços multisserviços, que têm, no Centro Comercial das Amoreiras, de 1985, de Tomás Taveira, um momento alto. O passo seguinte deste percurso é a proliferação da versão multissalas, permitindo oferta diversificada e em paralelo num único local. Esta possibilidade, que o emblemático Cinema Quarteto inaugura, vai apresentando versões de aspirações variáveis. Como refere a autora, tanto a lógica dos centros comerciais, como das multissalas se prendem uma estratégia de substituição - e concentração? - da própria vida urbana. As ações diversas fixadas 
num único e protegido, lugar; a oferta de uma possibilidade de opção ficcionada e condicionada.

Falar dos espaços lisboetas dedicados ao espetáculo das imagens em movimento é uma tarefa exigente e complexa. Principalmente quando se procura tratar também as dimensões sociocultural, urbana e arquitetónica do seu desenvolvimento. Neste livro, a vida de Lisboa e dos lisboetas vai sendo desenhada ao ritmo do desenvolvimento da importância dos cinemas. Estes, nascidos sem independência, só conquistada posteriormente, chegam ao final do século XX com novas estratégias relação com a vida urbana. A fechar, os novos modelos comerciais multifunções dissolvem o papel dos espectadores conferindo-lhes um mais mecânico papel de consumidores indiferentes. Também fica clara a crescente profissionalização destas salas e respetivos edifícios. Como consequência é possível identificar a profissionalização do projeto destas salas, assim com a responsabilidade dos decisores políticos e legislativos que em algumas situações redirecionam a história das salas de cinema lisboetas.

A inexistência de um encerramento em modo de conclusão é parcialmente compensada com o último dos subcapítulos, dedicado ao aparecimento mais recente das mutissalas e ao que a autora chama de "fenómeno Alvaláxia" (317-326). A reflexão sobre fatos e condições da projeção de cinema na atualidade, com a perda de relevância de conceitos como "espectadores" ou "cinemas", enquanto parte do desenho do espaço arquitetónico (323), leva, por um lado, a uma impossibilidade de se perceber o que acontecerá a esta prática de ver cinema num futuro próximo e, por outro lado, à aceitação de que a referência em que alguns dos cinemas do século XX lisboeta apresentados se constituíram - cultural, social e arquitetonicamente - não encontram paralelo nos atuais contentores do ver cinema.

A pequena dimensão de algumas fotografias assim como a ausência de peças desenhadas dos exemplos referidos - implantações, plantas, cortes e alçados - diminuem a amplitude das leituras desta leitura. De qualquer modo, os dados e inter-relações estabelecidas permitem uma multitude de aproximações que contribuem para o conhecimento efetivo sobre a cidade de Lisboa na sua relação com as salas de cinema e as vidas dos habitantes transformados em espectadores mais ou menos cinéfilos.

Mais do que a história da cidade pela mão do ato de ver cinema, consegue perceber-se uma mudança da vida da cidade e das suas variáveis espácio-sociais sublinhadas pelas salas e arquiteturas do cinema. Também é relevante a coexistência apresentada, em diversos momentos, das diferentes escalas: tanto aplicável à dimensão das salas como à amplitude de público que servia. Quando se observa a proliferação dos cinemas de bairro, surgindo em paralelo com algumas das mais relevante e icónicas salas de Lisboa, compreende-se a possibilidade de se perceber as dimensões plurais do cinema, ou seja, 
os diversos cinemas do ver-se cinema no contexto da cidade. Afinal, ainda e sempre a grande força que dinamiza e dá consistência a uma cidade: as vozes e as possibilidades múltiplas de se ser. Neste sentido, e não sem alguma ironia, poder-se-á perceber que os tempos de democracia foram muito mais uniformizados - e até limitadores - do que as anteriores décadas do século XX quando à pluralidade de arquiteturas e modos de se ver e ser cinema na cidade de Lisboa. 